\title{
Model OF INTElLigent MainTenanCE Systems
}

\author{
Milan Gregor, Michal Haluška, Miroslav Fusko, Patrik Grznár
}

University of Zilina, Univerzitna 8215/1, 01026 Zilina, Slovak Republic

\begin{abstract}
We are in a time when coming new generation of industrial automation, intelligent production, progress towards the Industry 4.0, advanced technologies and solutions for digital business. This all goes to the so-called e-Business, i.e. business over the internet. All this is of course, hand in hand with research and innovation. This new trends needs to be adapted also by Maintenance and Operations Management. In the article is a description of the design concept of integrated reconfigurable Maintenance system. Such a system after the introduction into the enterprise should address the role of an increasing the performance system in respect of costs incurred.
\end{abstract}

Keywords: technical services; intelligent agents; maintenance; reconfigurable maintenance systems, e-Business
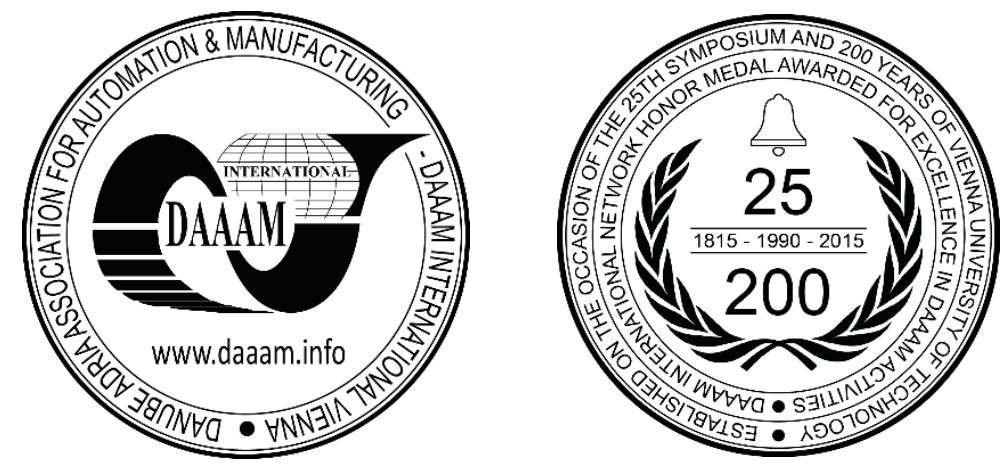

This Publication has to be referred as: Gregor, M[ilan]; Haluska, M[ichal]; Fusko, M[iroslav] \& Grznar, P[atrik] (2016). Model of Intelligent Maintenance Systems, Proceedings of the 26th DAAAM International Symposium, pp.10971101, B. Katalinic (Ed.), Published by DAAAM International, ISBN 978-3-902734-07-5, ISSN 1726-9679, Vienna, Austria

DOI: $10.2507 / 26$ th.daaam.proceedings.154 


\section{Intelligent maintenance systems and e-Business}

Predictive maintenance of plant floor assets is a critical component of the e-Manufacturing concept. Predictive maintenance systems, also referred to e-Maintenance in this document, provide manufacturing, and operating systems with near-zero downtime performance through use and integration of real-time and smart monitoring a performance assessment method. [19] These systems can compare a product's performance through globally networked monitoring systems to shift the degradation prediction and prognostics rather than fault detection and diagnostics. To achieve maximum performance from plant floor assets, it is possible through e-maintenance systems that can be used for monitor, analyse, compare, reconfigure, and sustain the system via a web-enabled. [13] In addition, these intelligent decisions can be harnessed through web-enabled agents and connect them to e-business tools (such as customer relation management systems, ERP systems, and e-commerce systems) to achieve smart and effective service solutions. [12] Remote and realtime assessment of machine's performance requires an integration of many different technologies including sensory devices, reasoning agents, wireless communication, virtual integration and interface platforms. [2]

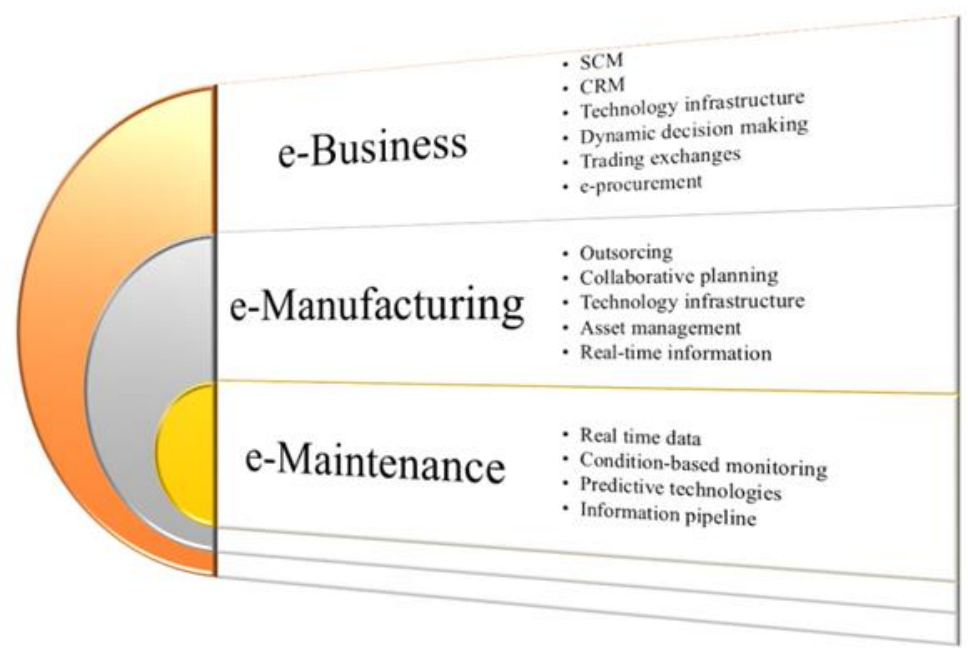

Fig. 1. Integration through e-Maintenance, e-Manufacturing and e-Business. [4]

Web-enabled and infotronics technologies play indispensable roles in supporting and enabling the complex practices of design and manufacturing by providing the mechanisms to facilitate and manage the integrated system discipline with the higher system levels such as SCM and ERP. [17] E-Maintenance is a major pillar that supports the success of the integration of e-Manufacturing and e-business. Figure 1 shows the integration among e-Maintenance, eManufacturing, and e-Business systems. If it is implemented properly, manufacturers and users will benefit from the increased equipment and process reliability with optimal asset performance and seamless integration with suppliers and customers. In order to further advance the development and deployment of the e-Manufacturing system, research needs can be summarized as follows: [14], [9]

- Predictive intelligence (algorithms, software, and agents) with a focus on degradation detection on various machinery and products. [20]

- Mapping of relationship between product quality variation and machine and process degradation.

- Data mining, reduction, and data-to-information-to-knowledge conversion tools.

- Reliable, scalable, and common informatics platform between devices and business, including implementation of wireless, Internet, and Ethernet networks in the manufacturing environment to achieve flexible and low-cost installations and commissioning.

- Data/information security and vulnerability issues at the machine/product level.

- Distributed and web-based computing and optimization and synchronization systems for dynamic decision making.

- Education and training of technicians, engineers, and leaders to make them capable of pacing with the speed of information flow and understanding the overall structure.

- Develop a new enterprise culture that resonates the spirit of e-manufacturing.

\section{Integration of reconfigurable maintenance concept in business}

A production quality depending from customer requirements requires the design of a product that meets customer ideas and accordingly it is necessary to configure a production system according to minimize possible deviations. The ability of the system reconfiguration has to be offset by changes in demand. It is necessary to have during the system 
configuration an available tool that provides a general view over the possibility of producing desired requirements. [18] Quality is affected by a number of factors that depend on the changes in the configuration. [16] Changes reflected to product platforms and system design influence configuration parameters. These changes may be used as indicators of the final quality. Assignment of tolerance and maintenance policy will reflect on the overall quality and production costs. The concept provides to wide enterprise prediction of possible failure, their causes and sharing good solutions. [11] Proposed reconfigurable maintenance system (Fig. 2) has diagnostic knowledge and service activities which supports intercompany maintenance cooperation. Information and productivity knowledge, diagnosis and evaluation activities could be shared among manufacturing companies. This approach of mutual cooperation significantly stimulates efficiency of system reconfiguration which is initialized during product design and identification of unreliability in the current system configuration. The collected data could give as valuable parameters for development of system reliability, sustainability, serviceability and safeguard factor in the life cycle of the system. [5]

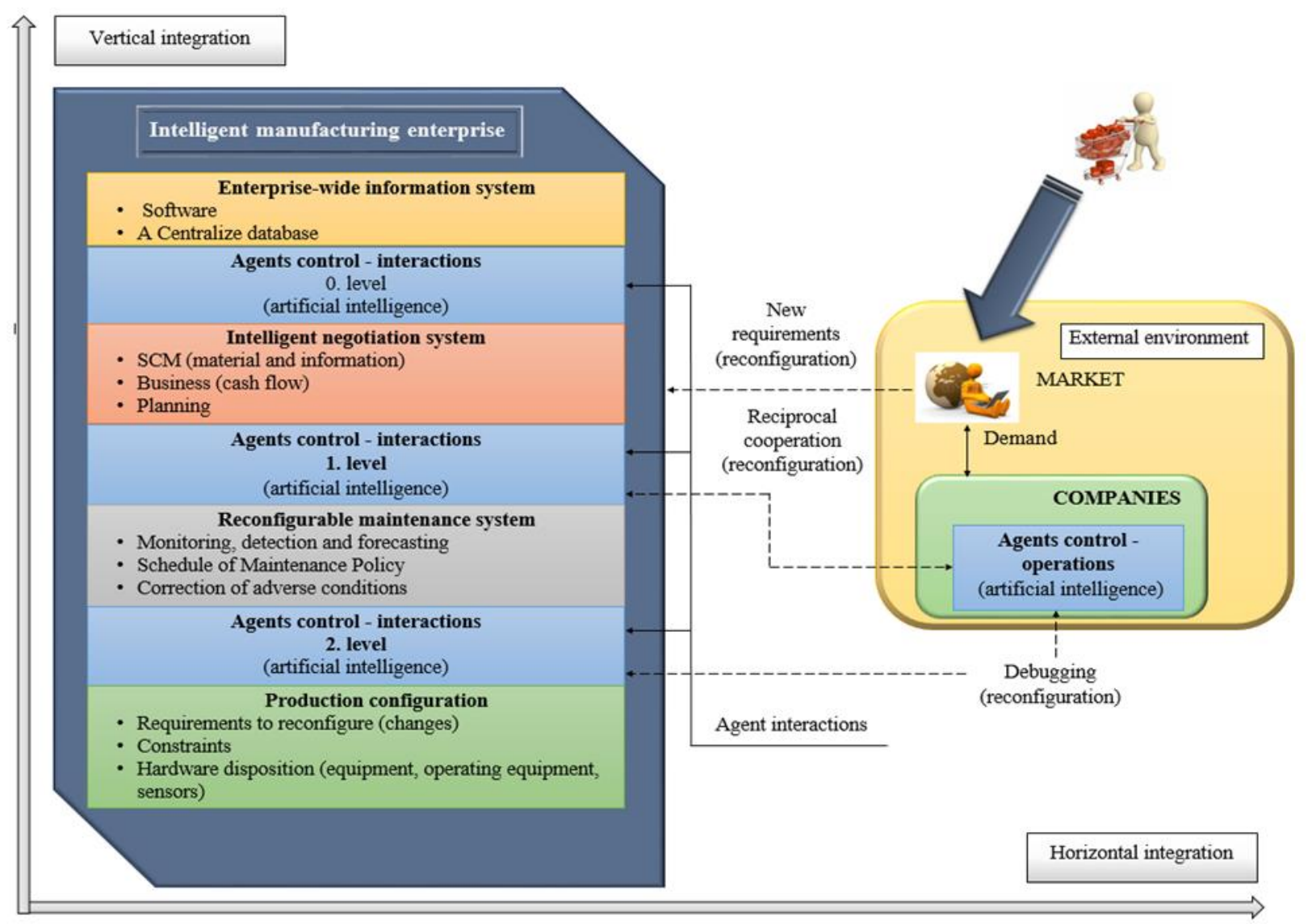

Fig. 2. Reconfigurable integrated maintenance system in the enterprise.

\section{Modular reconfigurable system maintenance}

Maintenance system has the competence to ensure the reliability of the production system, scheduling maintenance activities and perform optimization. The advantage lies in the concept (Fig. 3) of system-wide communication with the control center which allows remote maintenance activities which encourage value adding and cost reductions through the implement of a telecommunications network. [1] Modular subsystem has defined communication links based on a distributed architecture of management, which is designed based on the maintenance policy and planning maintenance activities. Monitoring module allows to perform surveillance activities through the sensor disposition of production equipment. Transmission of radio signals and following translations to restore the original sensor information constitutes a basic description of the data flow. Equipment mediates in a given method the relevant module data which is then analyzed in detail. [4], [3] 


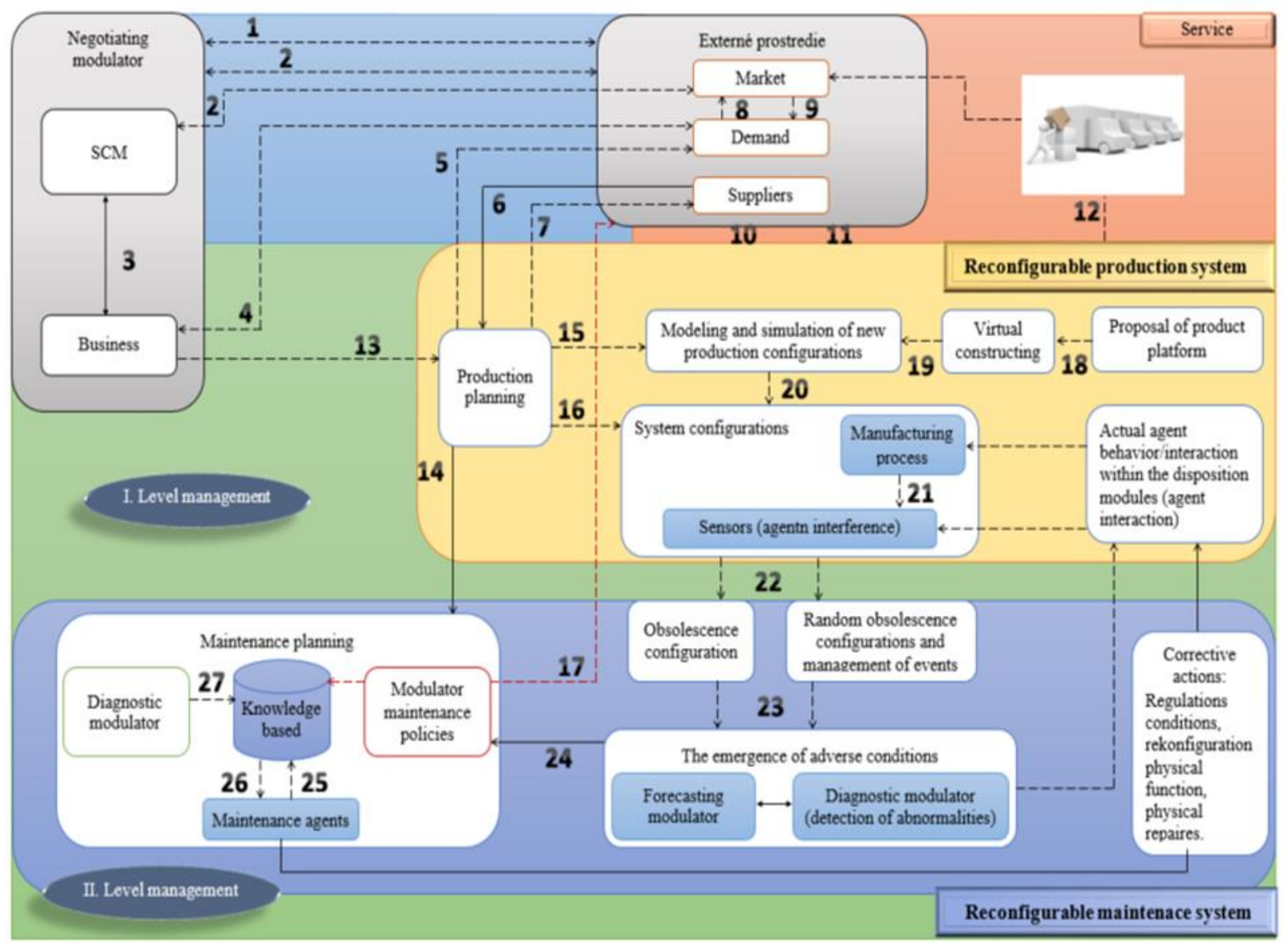

Fig. 3. The principle of maintenance activities in the enterprise based on reconfiguring the agent management activities. (1 - Service (alternatives, costs incurred); 2 - Material and information flow; 3 - Record keeping of transactions, materials and products; 4 - The flow of funds; 5 - The rate of yield generating capacity; 6 - The new manufacturing requirements; 7 - Orders; 8 - Supplying, prices, 9 - Sale, 10 - Repair; 11 - material, manufacture of components, services and requirements; 12 - Volumes produced / transfer; 13 - Financial recovery, supporting documentation (enabling efficient reconfiguration); 14 - Downtime (costs); 15 - Signaling unreliability configurations (adjustment available); 16 - Scheduling (Reconfiguration of logical functions); 17 - Intelligent maintenance cooperation; 18 Application of functional requirements; 19 - Structural design, 20 - Validated and Verified model; 21 - Transfer of data and events; 22 - Monitoring, 23 - Identified; 24 - Expected adverse conditions; 25 - Record repairs; 26 - Select repair; 27 - Archiving)

By given that this fact it is necessary to integrate enterprise reconfigurable modular maintenance system, which facilitates the rapid detection of adverse conditions and, consequently, made for preventive and remedial measures. In the reconfigurable production systems should be maintenance policy variable nature depending on system changes (e.g. Adding a module tool during the introduction of a new product within the product group). [6], [9]The knowledge base provides the best solution that can be used to assess systemic reliability. The exact interpretation of the interpretation of measurement parameters through these practices helps to identify the symptoms, trends and while providing diagnostic degradation causes. [9] Due to the fact the maintenance system requires the interpretation of measurement parameters based on historical data values. Through historical data and gained knowledge can be detect abnormalities in the system configuration. Due to the fact in system must be implemented expert system, which can in the future identify faults and perform maintenance activities. Known degradation trends, causes and proven solutions are used for expand the knowledge base, enabling appropriate corrective measures subject to reconfiguration activities with maximum efficiency. [7], [10]

\section{Conclusion}

Production environment was significantly changed. Nowadays, mass customization faces to competitive pressures and market fluctuations. If companies want to survive in this environment they must rapidly and with minimal costs respond to changes. [15] Attention of enterprises is then transferred to reducing costs, improving quality and ensuring cost-effective response by maintaining high production quality. On this basis it is necessary to integrated in the production reconfigurable maintenance system. This system must effectively deal with the adverse conditions in the production and ensure the overall reliability of production configurations. 


\section{Acknowledgements}

This paper was made about research work support: Kega 032 ŽU - 4/2015.

\section{References}

[1] B. Katalinic, I. Kukushkin, V. Pryanichnikov, D. Haskovic: „Cloud Communication Concept for Bionic Assembly System“ In: Procedia Engineering, international symposium on intelligent manufacturing and automation, DAAAM 2014; p. 1562-1568. ISSN 1877-7058., doi:10.1016/j.proeng.2014.03.156

[2] M. G. S. Aboelmaged: "E-maintenance research: a multifaceted perspective" In: Journal of Manufacturing Technology Management. Vol. 26, no. 5, 2015. p. 606-631. ISSN 1741-038X

[3] T. Sakai, S. Takata: "Reconfiguration management of remanufactured products for responding to varied user needs" In: CRIP Annals - Manufacturing Technology. 2012, Vol. 61, no.1, p. 21 - 26. ISSN: 0007-8506

[4] M. Gregor, J. Herčko, P. Grznár: "The Factory of the Future Production System Research" In: ICAC2015 Proceedings of the 21st International Conference on Automation and Computing, 11.-12.9.2015, Glasgow, ISBN: 978-0-9926801-0-7, p. 254-259

[5] M. Bugdol, P. Jedynak: "Integrated Management Systems”. Springer, 2015. 194 p. ISBN 978-3-319-10027-2

[6] M. Ben-Daya et. al.: "Handbook of Maintenance Management and Engineering” Springer, 2009. 741 p. ISBN $978-$ 1-84882-471-3

[7] M. Rakyta: "Increasing quality of production forecasting reliability and capability equipment" In: Safty. Quality. Reliability. 6th International Scientific Conference, 2015. The Technical University of Košice, 2015, p. 223-230. ISBN 978-80-553-2044-1.

[8] Y. Huang, et. al.: “Task-Oriented Adaptive Maintenance Support Systems" In: Journal of Computing and Information Science in Engineering. 2015, Vol. 15, no. 3. ISSN 1530-9827

[9] Y. Koren, U. Heisel, F. Jovane, T. Moriwaki, G. Pritschow, G. Ulsoy, H. Van Brussel: "Reconfugurable Manufacturing Systems" In: CRIP Annals - Manufacturing Technology. 1999, Vol. 48, no.2 . ISSN: 0007-8506, p. $527-540$

[10] I. Ng et. al.: "Complex Engineering Service Systems - Concepts and Research". Springer London. 2011.470 p., ISBN 978-0-85729-188-2

[11] M. Bučková, M. Krajčovič, J. Hnát: "New generation of manufacturing systems” In: TRANSCOM 2015:11-th European conference of young researchers and scientists: University of Zilina, 2015, s. 57-61. ISBN 978-80-5541044-9

[12] M. C. Spira, et. al.: "Method of providing Maintenance Services". United States Patent 2007, Patent No.: US 7269 569 B2

[13] L. Durica, P. Bubeník: "Framework for visualization of maintenance system” In: Manufacturing systems today and tomorrow. 8th Annual International Conference, 2014, The Technical University of Liberec, 6 p. ISBN 978-807494-150-4.

[14] M. Koc: Introduction to e-Manufacturing. Mitchigan University, USA, 2004, 97 str.

[15] A. H. C. Tsang: "Strategic dimensions of maintenance management" In: Journal of Quality in maintenance Engineering, 2015. 8(1), p. 7-39. ISSN: 1355-2511.

[16] V. Botti, A. Giret: Anemona: “A multi-agent methodology for holonic manufacturing systems”, London, 2008,214 s., ISBN 978-1- 84800-309-5

[17] J. Hnát, L. Závodská, M. Rakyta: "Logistics in the digital factory environment" In: InvEnt 2015 : industrial engineering from integration to innovation : proceedings of the international conference : University of Žilina, 2015, p. 84-87. ISBN 978-80-554-1038-8.

[18] K. A. Nasr, H.-G. Gross, A. v. Deursen: "Realizing service migration in industry - Lessons learned" In: Journal of Software Maintenance and Evolution Research and Practice. 2013; 25(6). DOI: 10.1002/smr.540. ISSN:1532-060X

[19] S. Wu, Y. Chen, Q. Wu, Z. Wang: "Linking component importance to optimisation of preventive maintenance policy" In: Reliability Engineering \& System Safety, v. 146, 2015. p. 26-32. ISSN 0951-8320

[20] M. J. Tippett, J. Bao: "Reconfigurable distributed model predictive control” In: Chemical Engineering Science, v. 136, 2015 p. 2-19. ISSN: 0009-2509 